\section{Carbon Dioxide Treatment Partially Overcomes Self-incompatibility in a Cacao Genotype}

\author{
Madhu Aneja and Thomas Gianfagna \\ Horticulture Department, Rutgers University, P.O. Box 231, New Brunswick, \\ NJ 08903
}

\author{
Edward Ng and Ignacio Badilla \\ Information Services Group, EFFEM Services, Mount Olive, NJ 07828 \\ Additional index words. pollen germination, plant breeding, Theobroma cacao
}

\begin{abstract}
Cacao (Theobroma cacao L.) contains self-compatible and self-incompatible genotypes. In the greenhouse, pollen germination and fruit set failed to occur after self-pollination of an incompatible genotype (IMC 30); however, if the self-pollinated flowers were enclosed in plastic vials for $6 \mathrm{~h}$ after pollination, pollen germination was $95 \%$ The promotive effect of enclosed pollination on pollen germination was due to the accumulation of $\mathrm{CO}_{2}(8.9 \% \mathrm{v} / \mathrm{v})$. Despite the high rate of pollen germination, fruit set was only $45 \%$. Seeds produced from self-pollinations using this technique were viable, with 95\% germination. Cross-pollination with 'Amelonado' pollen resulted in $100 \%$ pollen germination and $46 \%$ fruit set. Enclosure of cross-pollinated flowers did not improve the percentage of fruit set. Sections made through the ovary $48 \mathrm{~h}$ after enclosed self-pollination indicated that the majority of ovules contained a zygote; however, some ovules still contained unfused male and female gametes and polar nuclei. Self-incompatibility in this genotype is expressed at two stages in the process leading to fruit set. The first is at the pollen germination stage and can be overcome by $\mathrm{CO}_{2}$ treatment; the second is at the gametic fusion stage.
\end{abstract}

Self-incompatibility in cacao, which was first reported by Pound (1931), has been described as late-acting (i.e., the incompatibility reaction is not expressed until gametic fusion is initiated) (Cope, 1962a, 1962b). Pollen tubes of compatible and incompatible pollinations grow equally well through the style; however, incompatible self- or incompatible cross-pollinations result in $25 \%$ to $100 \%$ nonfusion ovules-ovules that have received male nuclei but have not undergone syngamy.

Glendinning (1960) and Lanaud et al. (1987) attempted to self-pollinate selfincompatible genotypes by using mixtures of pollen from a compatible genotype and its own pollen. Using this method, some selfed seeds were obtained.To our knowledge, no other report exists about overcoming self-incompatibility in cacao, although various techniques have been used in other plant species (see reviews by de Nettancourt, 1977; Shivanna and John, 1985).

We reported that enclosing flowers after self-pollination more than doubled the percentage of fruit set in cacao (Aneja et al., 1992); an event that occurred due to the accumulation of $\mathrm{CO}_{2}$ as a result of flower respira-

Received for publication 11 Jan. 1993. Accepted for publication 3 Aug. 1993. New Jersey Agricultural Experiment Station publication no. 12146-5-93, supported by state and Hatch Act funds, The cost of publishing this paper was defrayed in part by the payment of page charges. Under postal regulations, this paper therefore must be hereby marked advertisement solely to indicate this fact.

HortScience, Vol. 29(1), January 1994

\section{sample was removed
gas chromatography}

We observed the growth of pollen tubes in the pistil after fixing the tissue in $11 \% \quad \mathrm{Na}_{2} \mathrm{SO}_{3}$ for $24 \mathrm{~h}$. We opened the styles by lengthwise dissection after washing them with water and staining them with $0.1 \%$ aniline blue in $0.03 \mathrm{M}$ $\mathrm{K}_{3} \mathrm{PO}_{4}$ (Bowerman, 1975). The preparations then were observed under a fluorescent microscope (Leitz, Wetzlar, Germany).

Histological studies of the ovule and embryo sac were performed on 2- $\mu$ m-thick glycol methacrylate sections. Pistils harvested after 24,48 , and $72 \mathrm{~h}$ of pollination were fixed in $10 \%(\mathrm{v} / \mathrm{v})$ precooled acrolein at $0 \mathrm{C}$ for $24 \mathrm{~h}$. Following dehydration, the material was infiltrated and embedded in glycol methacrylate (Feder and O'Brien, 1968). Sections were cut using glass knives, stained with periodic acidSchiff's reagent (PAS), and counterstained with $1 \%$ aniline blue (Fisher, 1968). Photomicrographs were taken on a photomicroscope (Zeiss, Germany). The fruits that had set after enclosed self- and cross-pollinations were left on the tree to ripen. The fresh weights of ripe fruits and seeds were recorded along with the percentage of seed germination and the percentage of fruit that wilted before ripening. Flowers from a group of 36 trees were used as they became available over 4 months. Treatments were randomized over time, and the data were analyzed by orthogonal partitioning of the likelihood ratio chi square (G statistic) as described by Shaffer (1973).

\section{Results}

Pollen grains from self-pollination of the self-incompatible clone did not germinate in vivo (Table 1, Fig. 1A) or after pollination of excised flowers. However, if intact or excised flowers were enclosed after pollination, pollen germination was at least $95 \%$. (Table 1). Germination began $\approx 6 \mathrm{~h}$ after pollination (Fig. $\mathrm{lB})$, and within $1 \mathrm{~h}$ later, pollen tubes were seen at the base of the style. The $\mathrm{CO}_{2}$ concentration rose from ambient to $8.9 \%$ in $6 \mathrm{~h}$. Placing a $\mathrm{NaOH}$-saturated wick in the vials prevented pollen germination (data not shown) as previously reported for 'Amelonado' (Aneja et al., 1992).

Within $24 \mathrm{~h}$ after enclosed self-pollinations, male gametes were released from the pollen tubes, but syngamy or triple fusion was not observed in any of the ovules (Fig. 1 C). One of the synergids degenerated by this time, being characterized by an intense staining reaction

Table 1. Effect of $\mathrm{CO}_{2}$ treatment on pollen germination and fruit set in a self-incompatible cacao genotype.

\begin{tabular}{llrrr}
\hline \hline \multirow{2}{*}{$\begin{array}{c}\text { Pollination } \\
\text { treatment }\end{array}$} & \multirow{2}{*}{$\begin{array}{c}\text { Pollen } \\
\text { germination }\end{array}$} & \multicolumn{2}{c}{ Fruit set $^{y}$} \\
\cline { 4 - 5 } $\mathrm{CO}_{2}$ & Method & $(\%)$ & Percent & $\begin{array}{c}\text { No. } \\
\text { flowers }\end{array}$ \\
\hline- & Self & $0 \mathrm{a}$ & $0.0 \mathrm{a}$ & 15 \\
& Cross & $100 \mathrm{~b}$ & $45.6 \mathrm{~b}$ & 18 \\
+ & Self & $95 \mathrm{~b}$ & $44.8 \mathrm{~b}$ & 34 \\
& Cross & $100 \mathrm{~b}$ & $38.4 \mathrm{~b}$ & 26 \\
\hline
\end{tabular}

${ }^{2}+\mathrm{CO}_{2}$ treatment given by enclosing the flowers in plastic vials on the tree. 'Amelonado' was used in the cross pollinations.

${ }^{y}$ Percentage of flowers in which fruit set occurred. Mean separation by orthogonal partitioning of the likelihood ratio chi-square. 
for proteins. Fusion of male and female gametes occurred $48 \mathrm{~h}$ after pollination (Fig. ID), and the open self-pollinated flowers from the self-incompatible clone had abscised. The zygote was binucleolate, and the staining reaction of the cytoplasm showed an increase for total proteins. The majority of the ovules contained a zygote 48 or $72 \mathrm{~h}$ after pollination; however, some ovules in which male and female gametes were still unfused were encountered with the free nuclei lying in close proximity to each other in the embryo sac (Fig. $1 \mathrm{E}$ and $\mathrm{F}$ ).

Despite 95\% pollen germination for enclosed self-pollinations, the percent fruit set was $<50 \%$ (Table 1). Increasing the level of $\mathrm{CO}_{2}$ inside the vial (by injecting $1 \mathrm{ml}$ of $15 \%$ $\mathrm{CO}_{2}$ ) or increasing relative humidity (by adding a water-saturated wick) did not increase pollen germination or the percent fruit set (data not shown). Enclosing the flowers for an additional $6 \mathrm{~h}$ also did not increase fruit set; in fact, this treatment prevented fruit set entirely (data not shown).

When the flowers of the self-incompatible clone were cross-pollinated with 'Amelonado' pollen, percent fruit set was not significantly different from that obtained by enclosed self-pollination (Table 1). Moreover, enclosing the cross-pollinated flowers did not further enhance fruit set, as it did when 'Amelonado' flowers were self-pollinated (Aneja et al., 1992).

The seeds from the selfed incompatible clone obtained by the enclosed pollination technique had a high rate of viability, and $95 \%$ germinated. Although the fresh weight of the fruit obtained by enclosed self-pollination of the self-incompatible genotype was significantly greater than that of 'Amelonado' fruit from self-pollination (523 vs. $323 \mathrm{~g}, \mathrm{n}=35$ ), the fresh $(\approx 2.0 \mathrm{~g})$ and dry $(\approx 1.34 \mathrm{~g})$ weights of the seeds, the number of seeds per fruit $(33.7$ vs. 32.6), and the percentage of fruits that wilted before maturity ( 40.6 vs. 46.5 ) were not significantly different.

\section{Discussion}

Enclosure of self-pollinated cacao flowers for $6 \mathrm{~h}$ after pollination partially overcomes the self-incompatibility reaction and allows the production of selfed seeds. Carbon dioxide is the likely agent responsible for this effect, as $\mathrm{CO}_{2}$ accumulates in the vial to at least $8 \%$ in 6 $\mathrm{h}$ and absorbing the $\mathrm{CO}_{2}$ as it is produced prevents pollen germination and fruit set (Aneja et al., 1992). A high level of $\mathrm{CO}_{2}$ applied for a short period after pollination also has been shown to overcome sporophytic selfincompatibility in Brassica oleracea L. Capitata Group (Nakanishi and Hinata, 1973; Palloix et al., 1985; Taylor, 1982) and $B$. campestris L. (Dhaliwal et al., 1981), and gametophytic self-incompatibility in Trifolium repens L. (Douglas and Connolly, 1989). Ethylene has been reported to overcome gametophytic self-incompatibility in Lycopersicon peruvianum (L.) Mill. (Webb and Williams, 1988; Williams and Webb, 1987); however, we were not able to detect the presence of ethylene during the 6-h enclosed pollination period in cacao flowers (Aneja et al., 1992) and concluded that it did not play a significant role in cacao pollen germination.

In this study, we did not find any germinated pollen on flowers left open on the tree after self-pollination of the self-incompatible clone. However, Cope (1962a, 1962b) reported similar rates of pollen germination and tube growth in incompatible and compatible pollinations. We have no explanation for this difference. For events after pollen germination, our results were similar to Cope's results (1962a, 1962b), particularly the presence of some ovules with unfused nuclei inside the embryo sac $72 \mathrm{~h}$ after pollination.

From this study, it seems that selfincompatibility occurs at two stages in the process leading to fruit set: first at the stage of pollen germination, which can be overcome by $\mathrm{CO}_{2}$, and second at the stage of gametic fusion as has been previously reported (Cope, 1962a, 1962b). This hypothesis explains the low rate of fruit set $(45 \%)$ from enclosed self-pollinations of the self-incompatible genotype - a partial block to fruit set still exists at the stage of gametic fusion. Similarly, enclosed cross-pollinations using 'Amelonado' pollen are no more effective than open cross-pollinations. Although pollen from this source germinates on the stigma of the self-incompatible clone without $\mathrm{CO}_{2}$ treatment, 'Amelonado' exhibits a certain level of cross-incompatibility, perhaps at the stage of gametic fusion.

The technique of enclosed pollination of cacao flowers needs to be tested under field conditions. In Brassica, $\mathrm{CO}_{2}$-generating bombs have been used to overcome selfincompatibility (Nakanishi and Hinata, 1973, 1975; Nakanishi et al., 1969). Other techniques to overcome incompatibility, such as physical damage to the stigmatic surface (Roggen and Van Dijk, 1972), electric current (Roggen et al., 1972), and heat (Roggen and Van Dijk, 1976), are time consuming and require considerable skill. The method presented in this paper is simple, rapid, and effective in producing selfed seeds from a self-incompatible genotype under our greenhouse conditions, and if of general use, it may be useful in cacao breeding programs.

\section{Literature Cited}

Aneja, M., T. Gianfagna, E. Ng, and I. Badilla. 1992. Carbon dioxide and temperature influence pollen germination and fruit set in cocoa. HortScience 27:1038-1040.

Bowerman, E.H. 1975. The development of male gametophyte in situ under selfing and crosspollination in six genotypes of tetraploid vaccinium. PhD Diss., Rutgers The State Univ., New Brunswick, N.J.

Cope, F.W. 1962a. The mechanism of pollen incompatibility in Theobroma cacao. Heredity 17:157-182.
Cope, F.W. 1962b. The effects of incompatibility and compatibility on genotype proportions in populations of Theobroma cacao L. Heredity 17:183-195

de Nettancourt, D. 1977. Incompatibility in angiosperms. Springer-Verlag, New York.

Dhaliwal, AS., C.P. Malik, and M.B. Singh. 1981 Overcoming incompatibility in Brassica campestris L. by carbon dioxide, and dark fixation of the gas by self- and cross-pollinated pistils. Ann. Bet. 48:227-233.

Douglas, G.C. and V. Connolly. 1989. Selffertilization and seed set in Trifolium repens $\mathrm{L}$. by in situ and in vitro pollination. Theor. Appl. Genet. 75:7 1-75.

Feder, N. and T.P. O'Brien. 1968. Plant microtechnique:Some principles and new methods. Amer. J. Bet. 55: 123-142

Fisher, D.B. 1968.Protein staining of ribboned epon sections for light microscopy. Histochemie 16:92-96.

Glendinning,D.R.1960. Selfing of self-incompatible cocoa. Nature 187:170.

Lanaud, C., O. Sounigo, Y.K. Amefia, D. Paulin, P. Lachenaud, and D. Clement. 1987, New data on the mechanism of incompatibility in cocoa and its consequences on breeding. Café Cacao TM $31: 278-282$.

Nakanishi, T., Y. Esashi, and K. Hinata. 1969 Control of self-incompatibility by $\mathrm{CO}_{2}$ gas in Brassica. Plant Cell Physiol. 10:925-927.

Nakanishi, T. and K. Hinata. 1973. An effective time for $\mathrm{CO}_{2}$ gas treatment in overcoming self incompatibility in Brassica. Plant Cell Physiol. 14:873-879.

Nakanishi, T. and K. Hinata. 1975. Self-seed production by $\mathrm{CO}_{2}$ gas treatment in selfincompatible cabbage. Euphytica 24: 117-1 20.

Palloix, A., Y. Herve, R.B. Knox, and C. Dumas. 1985. Effect of carbon dioxide and relative humidity on self-incompatibility in cauliflower, Brassica oleracea. Theor. Appl. Genet. 70:628633.

Pound, F.J. 1931. Studies of fruitfulness in cacao II. First. Annu. Rpt. Cacao Res. (Trinidad). p. 2628.

Roggen, H.P.J.R. and A.J. Van Dijk. 1972. Breaking incompatibility in Brassica oleracea L. by steel brush pollination.Euphytica $21: 424-425$.

Roggen, H. P.J.R. and A.J. Van Dijk. 1976. Thermally aided pollination:A new method of breaking self-incompatibility in Brassica oleracea $\mathrm{L}$. Euphytica 25:643-646.

Roggen, H.P.J.R., A.J. Van Dijk, and C. Dorsmarr. 1972. Electric aided pollination: A method of breaking incompatibility in Brassica oleracea. Euphytica 21:181-184.

Shaffer, J.E. 1973. Testing specific hypotheses in contingency tables:Chi square partitioning and other methods. Psychol. Rpt. 33:343-348.

Shivanna, K.R. and B.M. Johri. 1985. The arrgiosperm pollen. Wiley Eastern Limited, New Delhi, India.

Taylor, J.P. 1982. Carbon dioxide treatment as an effective aid to the production of selfed seed in kale and brussels sprouts. Euphytica 31:957964.

Webb, M.C. and E.G. Williams. 1988. Effect of temperature, light, nutrients and carbon dioxide on the strength of the self-incompatibility response in detached flowers of Lycopersicon peruvianum. Ann. Bet. 61:395-404.

Williams, E.G. and M.C. Webb. 1987. Enclosure of pollinated flowers weakens the gametophytic self-incompatibility response in Lycopersicon peruvianum. J. Expt. Bet. 38:1756-1764. 